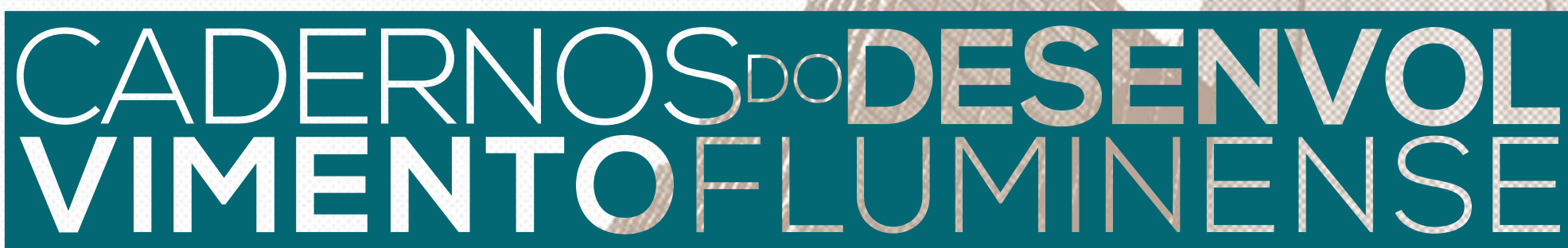

16

ANO $2019 \mid 1^{\circ}$ semestre

- Especialização produtiva - reflexos sobre o

desenvolvimento do estado do Rio de Janeiro;

- Relação entre renda petrolífera e melhoria na

qualidade de vida por municípios

confrontantes da Bacia de Campos;

- Desafios à gestão, ao desenvolvimento sustentável em Miracema;

- Inovação e Desenvolvimento Regional - uma análise sobre a produção científica da Universidade Estadual do Norte Fluminense e sua potencial contribuição para a sociedade;

- Perfil socioeconômico de feirantes do mercado municipal de Campos dos Goytacazes;

- Casa popular própria - ilusão ou solução;

- Capilaridade territorial na provisão de medicamentos básicos no estado do Rio de Janeiro;

- NudgeRio um caso de aplicação de Ciência Comportamental às Políticas Públicas;

- Mulher, política e cidade - reflexões analíticas.
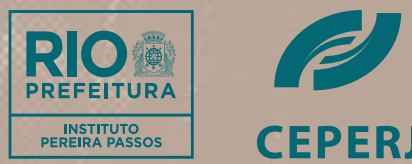


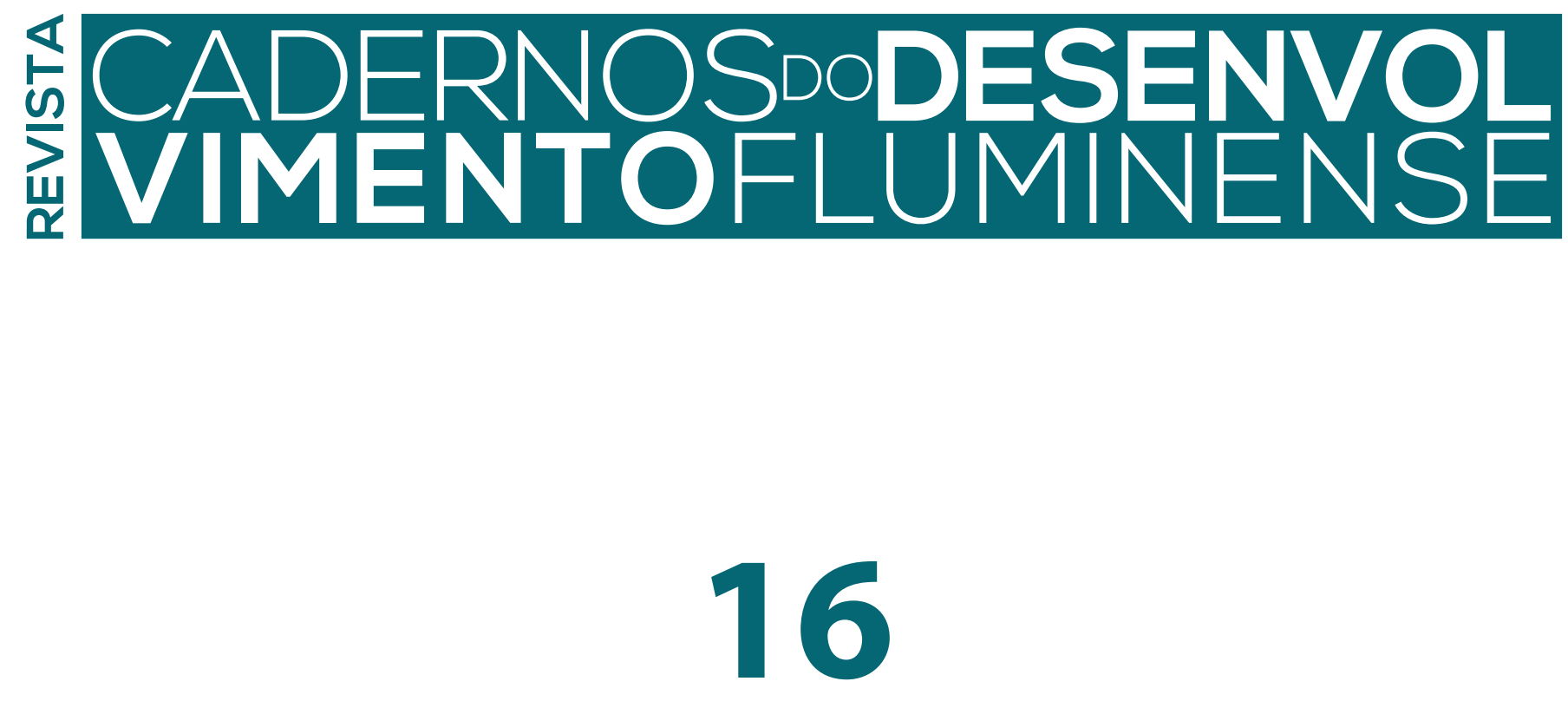

ANO 2019 $\mid 1^{\circ}$ semestre 
FUNDAÇÃO CENTRO ESTADUAL DE ESTATÍSTICAS, PESQUISAS E FORMAÇÃO

DE SERVIDORES PÚBLICOS DO RIO DE JANEIRO — CEPERJ

PRESIDÊNCIA

Pedro Castilho

ESCOLA DE GESTÃO E POLÍTICAS PÚBLICAS

Homero de Araújo Torres

CENTRO DE ESTATÍSTICAS, ESTUDOS E PESQUISAS

Fabio Odilon Alves Gomes

DIRETORIA DE CONCURSOS E PROCESSOS SELETIVOS

Lisandro Junior

DIRETORIA DE COOPERAÇÃO TÉCNICA E DES. INSTITUCIONAL

Tatiani Lisboa

DIRETORIA ADMINISTRATIVA E FINANCEIRA

Marcelo Serrano Peixoto

INSTITUTO PEREIRA PASSOS — IPP

DIRETOR-PRESIDENTE

Mauro Osorio

COORDENADOR TÉCNICO DE INFORMAÇÕES DA CIDADE

Carlos Krykhtyne

COORDENADORA TÉCNICA DE PROJETOS ESPECIAIS

Andrea Pulici

COORDENADOR DE COMUNICAÇÃO

Bruno Filippo 


\section{Editores}

EDITORES CIENTÍFICOS

Jorge Britto • UFF

Lia Hasenclever • Instituto de Economia - UFRJ

EDITOR EXECUTIVO

Bruno Filippo • IPP

\section{CONSELHO EDITORIAL}

Bruno Leonardo Barth Sobral • Faculdade de Ciências Econômicas - UERJ

Carlos Antonio Brandão • Inst. de Pesquisa e Planejamento Urbano e Regional - UFRJ

Fabiano Guilherme Mendes Santos • Instituto de Estudos Sociais e Políticos - UERJ

Glaucio José Marafon • Instituto de Geografia - UERJ

Jorge Nogueira de Paiva Britto • Faculdade de Economia - UFRJ

José Luis Vianna da Cruz • Centro de Pesquisa Candido Mendes - UCM

Lia Hasenclever • Inst. de Economia - UFRJ / Universidade Cândido Mendes

Campos - UCAM Campos

Luis Fernando Valverde Salandía • Instituto Pereira Passos

Luiz Martins de Melo • Instituto de Economia - UFRJ

Maria Alice Rezende de Carvalho • Depto. de Ciências Sociais - PUC RJ

Maria Lucia Teixeira Werneck Vianna • Instituto de Economia - UFRJ

Maria Helena de Macedo Versiani • Instituto Brasileiro de Museus

Marieta de Moraes Ferreira • Fundação Getúlio Vargas

Mauro Osorio • Faculdade Nacional de Direito - UFRJ

wMiguel Antonio Pinho Bruno - Escola Nacional de Ciências Estatísticas - IBGE /Fac. de Ciên-

cias Econômicas - UERJ / Mackenzie Rio

Nelson de Castro Senra • Escola Nacional de Ciências Estatísticas - IBGE

Paulo Alcântara • Universidade Cândido Mendes - UCAM

Paulo Knauss Mendonça • Depto. de História - UFF

Pedro Abramo • Instituto de Pesquisa e Planejamento Urbano Regional - UFRJ

Renata Lèbre La Rovere • Instituto de Economia - UFRJ

Roberto de Andrade Medronho • Instituto de Estudos em Saúde Coletiva - UFRJ

Rosélia Périssé Piquet • Centro de Pesquisa Candido Mendes - UCM

Sergio Ferraz Magalhães • Faculdade de Arquitetura e Urbanismo - UFRJ

Silvia Ramos • Centro de Estudos de Segurança e Cidadania - UCM

\section{REVISTA CADERNOS DO DESENVOLVIMENTO FLUMINENSE}

\section{COORDENAÇÃO}

Bruno Filippo

SECRETARIA EXECUTIVA

Ariana Falcão

REVISÃo

De responsabilidade dos autores

PROJETO GRÁFICO E DIAGRAMAÇÃO

Cláudio Novaes

R. São Francisco Xavier, 524/SI. 1050, Bloco FS - Maracanã

Rio de Janeiro • RJ - CEP 20550-013 - Telefone: (21) 2334-7313

revistacadernos.ceperj@gmail.com | www.e-publicacoes.uerj.br/ojs/index.php/cdf 



\section{Editorial}

Os Editores tem a satisfação de apresentar o conteúdo do $16^{\circ}$ número da REVISTA CADERNOS DO DESENVOLVIMENTO FLUMINENSE, que reflete o compromisso com uma reflexão acadêmica multidisciplinar sistemática tanto sobre contexto sócio-econômico-territorial do estado do Rio de Janeiro (ERJ), como também sobre orientações e práticas relevantes no campo das políticas públicas, orientadas para os enfrentamentos de desafios colocados em função de transformações contemporâneas da sociedade fluminense em suas múltiplas dimensões. Seguindo essa tradição, o presente número contempla tanto artigos baseados em reflexões de natureza mais geral, como abordagens mais focalizadas, em termos tanto do objeto de reflexão como do campo associado das políticas públicas. Traz colaborações de várias instituições do ERJ e abordagens de distintos campos disciplinares.

Em primeiro lugar, cabe destacar artigos com foco mais amplo em termos do diagnóstico socioeconômico do Estado do Rio de Janeiro, seja através de abordagens que contemplam tanto a configuração geral da estrutura produtiva, seja através de análises territorialmente mais localizadas da dinâmica socioeconômica. O artigo “Especialização produtiva: reflexos sobre o desenvolvimento do estado do Rio de Janeiro", de Henrique Cavalieri e Lia Hasenclever, analisa a evolução da estrutura produtiva do Estado do Rio de Janeiro, em comparação com a nacional. Ressalta-se a concentração em segmentos associados ao petróleo e mostra-se que essa especialização produtiva não tem se constituído em uma via de desenvolvimento virtuoso para o estado, pois tende a perpetuar e reproduzir heterogeneidades estruturais, refletidas em tendências de baixo crescimento econômico e vulnerabilidade externa.

No campo de um diagnóstico socioeconômico territorialmente mais localizado, o artigo "Relação entre renda petrolífera e melhoria na qualidade de vida por municípios confrontantes da Bacia de Campos", de Roberto Meireles Acruche, Ítalo de Oliveira Matias, Milton Erthal Jr, Fabio Freitas da Silva e Aldo Shimoya, tem como foco os nove municípios fluminenses pertencentes à Bacia de Campos. Por meio de uma pesquisa que usa o método de análise multicritério e dados do Índice FIRJAN (Federação das Indústrias do Rio de Janeiro) de Desenvolvimento Municipal, classifica os municípios e compara esta ordenação ao montante de rendas petrolíferas recebidas. Aponta-se que maiores níveis de royalties per capita não estão associados a melhores condições de desenvolvimento humano e constata-se uma dependência financeira dos municípios em relação à transferência e royalties acima de $70 \%$, com exceção da cidade de Macaé por concentrar a atividade petrolífera na região, sugerindo-se que a abundância de recursos naturais levou tanto a um afrouxamento fiscal e a uma tendência a negligenciar políticas públicas que estimulassem o desenvolvimento local.

Em sequência, o artigo "Desafios à gestão, ao desenvolvimento sustentável em Miracema (RJ)", de Paulo José de Mendonça Ribeiro, discute os impactos da criação de UC - Unidade de Conservação (UC) no município de Miracema, em 2010 como estratégia para promoção de um município "saudável e sustentável". Foi feita uma pesquisa de campo sobre: problemas de saneamento básico (lixo, esgoto, água e drenagem) e ambientais (erosão, desmatamento, contaminação da água), de modo a verificar em que medida a problemática socioambiental incorpora as questões relativas a qualidade de vida e bem-estar dos indivíduos e coletividades. As evidências coletadas sugerem que há mais custos que benefícios, particularmente no que se refere à sustentabilidade socioambiental, que representa um grande desafio para as políticas públicas.

O artigo "Inovação e Desenvolvimento Regional: uma análise sobre a produção científica da Universidade Estadual do Norte Fluminense e sua potencial contribuição para a sociedade", de Raquel Chaffin Cezario, Edson Terra Azevedo Filho e Henrique Rego Monteiro da Hora, pro- 
cura discutir, com base na experiência da Universidade Estadual do Norte Fluminense Darcy Ribeiro - UENF, o papel da universidade na sociedade, por meio da produção de conhecimento e da capacidade de induzir o desenvolvimento regional via inovação. A metodologia contempla uma abordagem quali-quantitativa mediante pesquisa bibliométrica no Banco de Dados Scopus. Constatou-se que a UENF tem gerado conhecimento relevante, por meio de publicações de documentos, principalmente na área das Ciências Agrárias e Biológicas, apresentando um potencial inovador capaz de contribuir com o desenvolvimento da Região desde que haja engajamento entre ela, governo e empresa, numa Hélice Tríplice.

Considerando um foco mais microscópico na abordagem da problemática do desenvolvimento socioeconômico local, o artigo "Perfil socioeconômico de feirantes do mercado municipal de Campos dos Goytacazes" de Graciela Aparecida Profeta, Raquel Chaffin Cezario, Elen Cristina de Mattos Lima e Vanuza da Silva Pereira Ney, procura caracterizar o perfil socioeconômico de feirantes de hortifrutícolas do mercado municipal de Campos dos Goytacazes, considerando aspectos relacionados aos canais de comercialização e as características econômicas que diferenciam os feirantes. Os resultados obtidos apontam que a renda mensal oriunda da feira era de extrema importância na composição da renda total da família, e, portanto, na sobrevivência das mesmas. Constatou-se também que os feirantes não usavam os circuitos curtos de produção que garantiriam a comercialização da produção local e que isso, além de não lhes fornecer produtos diferenciados para a venda, ainda implicava em perda de receita, pois acabavam competindo em condições desiguais com os supermercados da cidade.

$\mathrm{Na}$ transição entre abordagens de cunho mais analítico e abordagens com foco mais direcionado para a avaliação de políticas, o artigo "Casa popular própria: ilusão ou solução?", de Bianca Siqueira Gonçalves, Livia Maria de Souza Almeida Coura e José Luis Vianna da Cruz, é de natureza essencialmente conceitual, procurando discutir aspectos capazes de nortear a implementação de políticas habitacionais e urbanas, conectando a discussão do sonho de consumo da propriedade de um lugar para morar com as possibilidades de efetivação do direito à cidade, através de um revisão não sistemática da bibliografia sobre a origem da casa como mercadoria e objeto de desejo do trabalhador e sobre a questão da segregação sócio espacial à luz do Direito à Cidade. Ao mesmo tempo, procura-se articular essa discussão a aspectos importantes da estrutura e dinâmica da cidade, ressaltando-se o papel do planejamento urbano no sentido de mitigar a segregação socioespacial.

No campo mais operacional da avaliação de políticas, o artigo "Capilaridade territorial na provisão de medicamentos básicos no estado do Rio de Janeiro", de Eduardo Manhães e Lia Hasenclever, analisa a Política Pública de Assistência Farmacêutica (AF) nas mesorregiões do estado do Rio de Janeiro por meio da distribuição territorial das Unidades Básicas de Saúde (UBS) e dos estabelecimentos do Programa Farmácia Popular do Brasil. Aborda ainda a relação existente entre a instalação de unidades de AF com o volume populacional e a renda média per capita das mesorregiões no ano de 2018. A partir da construção de indicadores e da análise da correlação entre as variáveis, constata-se que, apesar de ter havido uma expansão da provisão de medicamentos, os estabelecimentos da rede credenciada são mais concentrados e os das UBS são mais dispersos no território, o que indica um melhor desempenho destas últimas em termos de distribuição territorial.

Ainda no campo da operacionalização de políticas públicas, o artigo "NudgeRio: um caso de aplicação de Ciência Comportamental às Políticas Públicas", de Otávio Morato de Andrade, discute possíveis soluções para políticas públicas baseadas em insights e fundamentos teóricos da Economia Comportamental, mais conhecidos como Nudges, termo que sugere a associação de incentivos comportamentais para reverter falhas cognitivas e que podem inspirar a criação de novas estratégias de aderência às políticas públicas. Especificamente, procura-se discutir com exemplos práticos de aplicações de Nudges no âmbito da governança estatal, em especial, o caso da NudgeRio, unidade criada na Prefeitura da Cidade do Rio. Refere-se ao caso da implementação do Programa Líderes Cariocas (PLC), coordenado pelo Instituto Fundação João Goulart (IFJG), que procura selecionar servidores públicos com perfil de liderança positiva e capacitá-los para assumir posições proeminentes na administração pública municipal. 
Por fim, no campo mais amplo da representação política, mas ainda com claros desdobramentos na definição de políticas públicas, o artigo "Mulher, política e cidade: reflexões analíticas", de Aimée Seixas de Sousa e María Gabriela Scotto, discute as relações entre mulheres, cidade, feminismo e participação em espaços de representação política. O caso da pesquisa em foco é a presença feminina na Câmara Municipal do Rio de Janeiro. Especificamente, a partir da implementação das cotas eleitorais para mulheres, busca-se discutir as relações entre a participação política e o direito à cidade sob a concepção de gênero. Argumenta-se que, numa perspectiva feminista, é possível pensar a mulher presente e atuante na política municipal como planejadora do espaço urbano e da vida das cidades, avaliando de maneira mais clara suas pretensões, interesses e demandas, apontando-se a necessidade de autonomia feminina no que diz respeito aos seus direitos como cidadãs e às escolhas sobre o acesso e a função do espaço público.

O conjunto de artigos presentes nesse número da REVISTA CADERNOS DO DESENVOLVIMENTO FLUMINENSE reflete o caráter multidisciplinar da discussão sobre o desenvolvimento fluminense e o compromisso em relação à avaliação de políticas públicas que norteiam a nossa linha editorial. Além disso, destacamos o compromisso do Conselho Editorial e das instituições de apoio no sentido de dar maior celeridade à avaliação das submissões e à atualização do processo de edição. É com base nessa perspectiva que reiteramos o convite à comunidade acadêmica para novas submissões que enriqueçam ainda mais a Revista. 



\title{
Mulher, política e cidade: reflexões analíticas
} Women, politics and the city: analytical reflections

\author{
Aimée Seixas de Sousa ${ }^{1}$ \\ María Gabriela Scotto ${ }^{2}$
}

\begin{abstract}
RESUMO
O objetivo do artigo é abordar, sem pretensão de esgotar o assunto, algumas temáticas e discussões que consideramos fundamentais para evidenciar nossa perspectiva analítica para a compreensão das relações entre mulheres, cidade, feminismo e participação em espaços de representação política. Este artigo é parte de uma pesquisa, ainda em andamento, cujo objetivo é analisar a presença feminina na política, mais especificamente na Câmara Municipal do Rio de Janeiro. Levando em conta a existência e a implementação das cotas eleitorais para mulheres, buscaremos pensar as relações entre a participação política e o direito à cidade sob a concepção de gênero. Neste trabalho, partiremos de uma revisão de literatura que traz uma exposição contextual, histórica e teórica acerca da presença feminina nas esferas representativas de poder. Não deixaremos de lado a análise dos termos conceituais e teóricos do direito à cidade para compreendermos a questão do direito feminino à cidadania plena na vida das cidades.
\end{abstract}

PALAVRA-CHAVE: Mulheres. Política. Direito à Cidade. Cotas. Feminismo.

\begin{abstract}
The objective of the article is to address, without pretension to deplete the subject, some themes and discussions that we consider fundamental to highlight our analytical perspective for understanding the relationships between women, the city, feminism and participation in spaces of political representation. This article is part of a research, still in progress, which objective is to analyze the female presence in politics, more specifically in the Lower Legislative Assembly of Rio de Janeiro. Taking into account the existence and implementation of electoral quotas for women, we will seek to think about the relationship between political participation and the right to the city under the concept of gender. In this work, we will start from a literature review that brings a contextual, historical and theoretical exposition about the female presence in the representative spheres of power. We will not leave aside the analysis of the conceptual and theoretical terms of the right to the city to understand the issue of the female right to full citizenship in the life of cities.
\end{abstract}

KEYWORDS: Women. Politics. Right to the City. Quotas. Feminism.

\section{Introdução}

O artigo em questão é resultado de uma pesquisa em fase de desenvolvimento, que se pergunta sobre os efeitos da presença feminina na política em âmbito legislativo, a nível municipal, levando em consideração a existência de políticas de cotas para mulheres que visam garantir legalmente um determinado número (ou percentual) de vagas para candidaturas femininas em eleições municipais. Embora o foco seja a política de cotas no Brasil e os efeitos das sua implementação na cidade do Rio de Janeiro, a pesquisa

1 Bacharel em Relações Internacionais. Mestranda do Programa de Pós Graduação em Desenvolvimento Regional, Ambiente e Políticas Públicas da Universidade Federal Fluminense (PPGDAP/UFF), Campos dos Goytacazes, Brasil. Endereço eletrônico: seixasaimee@gmail.com

2 Doutora em Antropologia Social. Professora do Departamento de Ciências Sociais da UFF Campos (COC/ESR) e professora do quadro permanente do Programa de Pós Graduação em Desenvolvimento Regional, Ambiente e Políticas Públicas (PPGDAP/UFF), Campos dos Goytacazes, Brasil. Endereço eletrônico: mgscotto@id.uff.br 
objetiva estabelecer um diálogo comparativo com outras duas cidades que, assim como o Rio, podem ser consideradas "cidades globais" ${ }^{\text {. }}$ Para isso será feita uma análise aprofundada da cidade do Rio de Janeiro, capital do Brasil entre os anos de 1763 a 1960, se perguntando pelas especificidades locais à luz dos casos de Buenos Aires e Cidade do México - capitais de Argentina e México, respectivamente.

Como marco temporal, nos concentramos no período que se inicia com a vigência da Convenção para a Eliminação de todas as Formas de Discriminação contra a Mulher (CEDAW)4', em 1981, até o ano de 2018. O triênio 2016-17-18 terá especial destaque na análise, visto que são anos em que ocorreram eleições mais recentes nas cidades investigadas ${ }^{5}$. A CEDAW possui 30 artigos $^{6}$ e foi aprovada em 1979 pela Assembleia Geral da ONU visando combater a exclusão sofrida pela mulher exclusivamente por conta de seu sexo, marcando a definição de direitos específicos delas ao levar em conta a própria Declaração Universal de Direitos Humanos (DUDH) da Organização das Nações Unidas, ratificada em 1948. Optamos por desenvolver a pesquisa a partir do momento em que valida-se tal Convenção pois esta assinala obrigações estatais que devem promover a igualdade de direitos para a mulher em âmbito civil, social, cultural, político, econômico etc., buscando cessar a violação dos princípios básicos relacionados à dignidade humana e descritos na DUDH.

Contudo, não podemos deixar de mencionar as importantes conquistas das mulheres em relação ao direito de votar e de se candidatar, anteriores à CEDAW. No Brasil, o direito ao voto feminino se dá no ano de $1932^{7}$ com a reformulação do Código Eleitoral ${ }^{8}$ realizada durante o governo do então presidente Getúlio Vargas através do Decreto no 21.076. Segundo Teresa Cristina de Novaes Marques (2018), quando tomaram conhecimento das intenções de reforma, feministas de entidades políticas como a Federação Brasileira pelo Progresso Feminino levaram a causa a Getúlio, que teria se mostrado aberto à ideia. (MARQUES, TCN. 2018) Assim, na eleição para a Assembleia Nacional Constituinte, em 1933, a mulher já podia votar e ser votada. No ano seguinte, em 14 de outubro de 1934, acontecem as eleições para as assembleias legislativas estaduais e para a Câmara dos Deputados, em que dez mulheres se elegem deputadas em todo o Brasil ${ }^{9}$.

Tendo em vista que este trabalho buscará tratar do caso específico das vereadoras cariocas, é interessante mencionar que, como resultado das eleições municipais de 1976, elegem-se as primeiras duas mulheres para a Câmara Municipal do Rio de Janeiro ${ }^{10}$. Diante de um sistema bipartidário ${ }^{11}$ imposto pelo regime

3 As cidades mundiais ou globais são cidades que produzem uma ampla gama de atividades, sendo consideradas centros politicos em diversos níveis de atuação, centros de comércio nacional e internacional, centros de serviços financeiros e bancários, centros de atividade profissional avançada de todas as áreas, de coleta e difusão de informações, de consumo, de arte, de cultura e entretenimento. (HALL, 1966)

4 Disponível em http://www.onumulheres.org.br/wp-content/uploads/2013/03/convencao_cedaw1.pdf

5 É importante esclarecer que esta pesquisa se iniciou antes da realização das eleições de 2019 na Argentina. Os dados levantados sobre a cidade de Buenos Aires são referentes às eleições do ano de 2017.

6 Para acessar questões específicas acerca dos direitos políticos das mulheres, olhar a Parte II do documento da Convenção.

$7 \quad$ No Rio Grande do Norte, a lei n 660 de 25 de outubro de 1927 já dava às mulheres potiguares o direito de votar. Naquele ano, Celina Guimarães Viana foi, então, a primeira mulher a se inscrever como eleitora no Brasil.

8 O código considerou eleitor "o cidadão maior de 21 anos, sem distinção de sexo". O voto feminino era facultativo.

9 A Constituição de 1934 aprovou a igualdade de direitos entre homens e mulheres, desde que fossem alfabetizados e maiores de 18 anos. $\mathrm{O}$ voto feminino continuou sendo facultativo, exceto para servidoras públicas, que eram obrigadas a votar.

10 Desde 1891, logo após a proclamação da República, até o ano de 1960, a Câmara do Rio de Janeiro era a Câmara do Distrito Federal, ou seja, não possuía uma configuração municipal. A partir de 1960, com a transferência do Distrito Federal para Brasília, o que hoje é o município do Rio de Janeiro passa a constituir o estado da Guanabara. É apenas em 1975, com a fusão dos estados do Rio de Janeiro e da Guanabara, que a cidade do Rio passa a ser a capital do estado do Rio de Janeiro. Com a realização das eleições municipais de 1976, a nova Câmara Municipal tem sua primeira legislatura no ano de 1977. Maduro ainda ressalta que "Após um intervalo de 18 anos entre as últimas eleições para a Câmara do Distrito Federal e as de 15/11/76, a maioria do eleitorado ficou sem noções muito precisas acerca do papel exercido por um vereador" (1980, p. 194)

11 O bipartidarismo vigorou no Brasil entre os anos de 1966 a 1979. Durante esse período, o cenário político brasileiro era composto apenas pela ARENA, partido do governo, e o MDB, partido da oposição. 
militar (1964-1985), Bambina Bucci é eleita com 66.577 votos como representante do Movimento Democrático Brasileiro (MDB), enquanto Daisy Lúcidi, representando a Aliança Renovadora Nacional (ARENA), elege-se com 51.134 votos. (MADURO, 1980)

Considera-se aqui que a participação da mulher na vida política no âmbito da luta parlamentar para a criação e instituição de políticas públicas que possibilitem a melhoria na qualidade de vida de todas as mulheres é de extrema importância no campo do planejamento urbano e regional. O fato de serem mulheres, no entanto, não garante a existência de pautas feministas nas agendas das legisladoras. Por esta razão, para aprofundar nestas questões, a pesquisa busca identificar o perfil das representantes eleitas em cada um dos municípios estudados a fim de elucidar as questões do ponto de vista feminino a respeito da cidade, no contexto da política municipal, fazendo uma reflexão sobre o direito à cidade sob a ótica de gênero ao discutir o direito da mulher ao governo, à cidadania, à política e à esfera pública. A partir daí é que pretendemos compreender as dificuldades estruturais enfrentadas no diálogo feminino com a cidade e com o dia-a-dia da sociedade urbana.

O estudo se sustenta em pesquisa bibliográfica, documental e outras fontes secundárias, tais como leis, decretos e discursos, construindo uma investigação que visa traçar a evolução, as diferenças e os resultados das legislações de cotas nas diferentes localidades analisadas. A câmara municipal e as vereadoras do município do Rio de Janeiro serão estudadas de maneira aprofundada através da realização de entrevistas e pesquisa de campo.

Por ser uma pesquisa em andamento, partimos, neste artigo, de uma revisão de literatura que abordará algumas temáticas e discussões fundamentais para que se possa evidenciar nossa perspectiva analítica relativa às relações entre mulheres, cidade e política municipal.

Nesse sentido, o artigo se divide em quatro seções, além desta introdução e das considerações finais: primeiramente, uma análise contextual e histórica do surgimento das cotas para mulheres na América Latina. Logo após, uma apresentação acerca da evolução das cotas eleitorais e da presença de mulheres nos legislativos locais das cidades da amostra. Em seguida, faremos uma reflexão teórica inicial sobre a participação da mulher na política institucional no contexto latino-americano. E, por fim, uma breve abordagem da problemática do direito à cidade.

\section{A experiência das leis de cotas eleitorais para mulheres}

Segundo Clara Araújo (1998), as assimetrias relativas aos direitos políticos das mulheres levaram ao questionamento das práticas políticas tradicionais por parte do feminismo na América Latina. Paralelamente, esse movimento começa a pensar em formas de intervenção mais diretas sobre as vias de acesso às arenas decisórias.

Foi nesse contexto que entraram em cena as propostas de leis de cotas para mulheres na política, que passaram a fazer parte da agenda dos partidos e governos, alcançando até mesmo dimensões internacionais e assumindo importância central nos debates sobre mulher e política. Observa-se, então, que o movimento feminista latino-americano possui ligação direta com a manifestação de formas de afirmações políticas que rompem com os limites da inclusão.

Segmentos sociais historicamente excluídos das esferas de representação política, como a população indígena, os negros e as mulheres, começam a aderir às lutas a favor de sua inclusão nos espaços de poder, reivindicando por transformações em suas estruturas internas.

Em grande parte da América Latina, inclusive no Brasil, as particularidades do cenário político se refletiram no surgimento de novos sujeitos coletivos no âmbito da democracia e da cidadania liberal ${ }^{12}$. As democracias emergentes do final dos anos 1980 abarcavam as demandas por direitos políticos e pela inclusão de todos os

\footnotetext{
12 Esse tipo de cidadania expressa relações sociais de tipo capitalista. Conforme Marshall (1967), a cidadania liberal refere-se aos direitos civis, políticos e sociais. Para ele, "O elemento civil é composto dos direitos necessários à liberdade individual - liberdade de ir e vir, liberdade de imprensa, pensamento e fé, o direito à propriedade e de concluir contratos válidos e o direito à justiça. Este último difere dos outros porque é o direito de defender e afirmar todos os direitos em termos de igualdade com os outros e pelo devido encaminhamento processual. [...] Por elemento político se deve entender o direito de participar no exercício do poder político, como um membro de um organismo investido da autoridade política ou como um eleitor dos membros de tal organismo. [...] $\mathrm{O}$ elemento social se refere a tudo o que vai desde o direito a um mínimo de bem-estar econômico e segurança ao direito de participar, por completo, na herança social e levar a vida de um ser civilizado de acordo com os padrões que prevalecem na sociedade." (MARSHALL, 1967, p. 63-64)
} 
segmentos sociais na nova configuração política que se estabelecia, mesclando as lutas por reconhecimento com a luta pela redemocratização ${ }^{13}$. (ARAÚJO, 1998)

Quanto ao caso brasileiro, Clara Araújo (1998) expõe que, após uma série de direitos legais conquistados pelas mulheres no momento da elaboração da Constituição de 1988, elas passam a considerar ainda mais a relevância de sua participação, requerida com base em uma afirmação de gênero, dentro das instituições políticas. A fins da década de 80 , as mulheres desempenham um importante papel através de sua intensa atuação em eventos políticos, tematizando publicamente - e de maneira incisiva - suas reivindicações diante de um contexto de crescente participação da sociedade brasileira. Nesse sentido, essas mulheres demonstram a importância e a necessidade de uma cultura política mais representativa e democrática.

A visão feminista acerca dessa participação, bem como o conhecimento de experiências de diferentes mulheres dentro dessa temática, foram ampliados quando mulheres brasileiras - sejam elas representantes políticas ou militantes - começam cada vez mais a marcar presença em encontros internacionais, como a Conferência das Nações Unidas sobre o Meio Ambiente e o Desenvolvimento, no Rio de Janeiro (1992), a Conferência Mundial de Direitos Humanos, em Viena (1993) e a Conferência Internacional sobre População e Desenvolvimento, no Cairo (1994). Esses encontros são fruto de um intenso ciclo de atividades da ONU em torno da reflexão feminista, iniciado no fim dos anos 1970 e que tem a instituição da CEDAW como um grande marco que iria impulsionar uma crescente influência ideológica e prática sobre o movimento de mulheres, ganhando bastante força nos anos 1990.

Diante dessa conjuntura, ocorre também a IV Conferência da ONU sobre a mulher, de 1995, em Beijing. É a partir daí que reorienta-se definitivamente o foco para o conceito de gênero e criam-se os caminhos para a viabilização da adoção das cotas eleitorais, já que a conferência conduziu os governos a assumirem uma postura favorável à participação política feminina. (MARQUES, D. 2018)

A adesão da perspectiva de gênero à agenda da ONU foi celebrada por feministas de diferentes partes do mundo, que passaram a considerar a Conferência de Beijing como ferramenta indispensável para a orientação de suas reivindicações. Essa Conferência, no entanto, "levou grandes segmentos do Movimento a se limitarem ao monitoramento estatal profissionalizado (especialmente via ONGs) da plataforma gerada nesse encontro." (CISNE, 2015, n.p) As Nações Unidas buscavam estabelecer uma hegemonia de seu feminismo pautado na "análise" isolada de gênero, que se difundiu fortemente no Brasil, sem considerar as articulações de raça e de classe. Com a adaptação das ONGs aos interesses da ONU e de outras agências e organismos internacionais, fica evidente, portanto, o momento de institucionalização do feminismo.

Esse processo de "onguização" e a absorção das atividades das organizações de mulheres pela ONU geram, segundo Jules Falquet (2011), uma despolitização do movimento feminista e sua perda de autonomia e radicalidade. É importante colocar também que toda essa ronda de conferências abarcou apenas uma elite feminista que podia estar presente nesses eventos e tornam-se expertas de gênero, recebendo uma série de vantagens. Paralelamente, devido a uma tendência hegemônica de perda da configuração do feminismo como movimento social, a militância de rua diminui ${ }^{14}$.

\footnotetext{
13 Souza-Lobo (2011) enfatiza que, no Brasil, esse momento é marcado pela grande dimensão e heterogeneidade do movimento de mulheres. Logo em seguida, ocorre uma expansão do discurso feminista dentro dos partidos políticos, porém as práticas autônomas diminuem. A partir de 1982, com a criação dos Conselhos da Mulher, as feministas se dividem entre as que queriam ocupar cargos governamentais e as que insistiam em preservar os movimentos como seu único espaço. Nesse caso, "[...] o problema reside não na diversificação das práticas, mas na submissão voluntária ou não dos movimentos à iniciativa dos órgãos estatais ou na substituição dos movimentos pelo Estado ou na confusão entre movimento e Estado, visível na forma dos Conselhos que, no discurso de algumas, seria um representante dos movimentos." (SOUZA-LOBO, 2011, p. 227)
}

14 Ainda assim, como apontado por Carmen Silva (2011), resistiam formas mais radicais do movimento feminista que se opunham a esse cenário. Esses grupos sempre estiveram em combatividade, debatendo alternativas ao neoliberalismo e se mobilizando, por exemplo, contra a Área de Livre Comércio (Alca) e a Organização Mundial do Comércio (OMC). 


\section{Mulheres nos legislativos locais latino-americanos}

No ano de 2016, a porcentagem média de vereadoras eleitas na América Latina era de 29,2\% Apesar desse número estar acima da média mundial no quesito representatividade feminina no parlamento - graças em grande parte às medidas afirmativas adotadas assinaladas na CEDAW - é nítida a discrepância entre os países da região quando analisados individualmente.

O conhecimento acerca do sistema eleitoral adotado em cada localidade é crucial para a compreensão de suas respectivas realidades no sentido da representação, já que o grau de efetividade de uma medida afirmativa, como a lei de cotas para mulheres, tem relação direta com o tipo de lista ${ }^{16}$ vigente.

O Rio de Janeiro adota a cota mínima de $30 \%$ em um sistema de listas eleitorais abertas. Na cidade de Buenos Aires, no contexto das eleições de 2017, prevalecia ainda a adoção da mesma cota de $30 \%$, porém em um sistema de listas fechadas e ordenadas de modo que houvesse pelo menos uma mulher a cada três candidatos listado ${ }^{17}$. Na Cidade do México, onde também valem as listas de tipo fechado, vigora, desde 2014, a lei de paridade de gênero na competência eleitoral, garantindo a presença de $50 \%$ de mulheres nos legislativos a níveis federal e local (ver Quadro 1).

QUADRO 1 - Evolução das cotas para mulheres nas cidades abordadas

\begin{tabular}{|cccc|}
\hline Localidade & Ano de adoção da medida & $\begin{array}{c}\text { Porcentagem } \\
\text { mínima da cota }\end{array}$ & $\begin{array}{c}\text { Porcentagem de mulheres } \\
\text { no legislativo local }\end{array}$ \\
\hline Buenos Aires, Argentina & 1991 & $30 \%$ & $36,7 \%$ \\
& 2018 & $50 \%$ & (Eleições 2017) \\
Cidade do México, México & 1996 & $30 \%$ & $50 \%$ \\
& 2008 & $40 \%$ & (Eleições 2018) \\
Rio de Janeiro, Brasil & 2014 & $50 \%$ & $13,7 \%$ \\
& 1995 & $20 \%$ & (Eleições 2016) \\
\hline
\end{tabular}

Fonte: Elaboração própria com base em dados do Observatório de Igualdade de Gênero da América Latina e do Caribe (CEPAL), da Câmara Municipal do Rio de Janeiro, do Congreso de la Ciudad de México e da Legislatura de la Ciudad Autónoma de Buenos Aires.

Ainda que não tenhamos, neste momento, condições de estabelecer uma relação direta entre "mais mulheres" e cidades mais amigáveis e inclusivas para elas, é importante o aumento da presença feminina nos espaços formais de representação para garantir processos mais democráticos de governança urbana. Posteriormente, buscaremos nos aprofundar no caso do Rio de Janeiro a fim de determinar as consequências efetivas, para o planejamento urbano, da presença de mulheres nas arenas de poder.

Embora fuja aos limites deste artigo, é importante mencionar que trabalhamos com a hipótese - a ser verificada ao longo da pesquisa - de que, apesar das ações afirmativas implementadas no Rio de Janeiro, em Buenos Aires e na Cidade do México, o planejamento das transformações urbanas ainda é majoritariamente realizado em um cenário em que a participação de mulheres

15 Observatório de Igualdade de Gênero da América Latina e do Caribe: Mulheres vereadoras eleitas. Disponível em https://oig. cepal.org/pt/indicadores/mulheres-vereadoras-eleitas

16 As direções partidárias têm seu poder ampliado quando são as listas fechadas as que vigoram no sistema de representação proporcional. Ainda que os partidos sejam tradicionalmente resistentes à presença política de mulheres, esse tipo de lista é a mais favorável à efetividade das cotas, visto que o preordenamento dos candidatos gera um resultado quase automático. No caso das listas abertas, a reserva de vagas de candidaturas femininas é pouco eficiente, pois além de os candidatos disputarem individualmente o voto popular, as mulheres ainda recebem poucos recursos para realizarem suas campanhas. (MIGUEL, 2014).

17 A lei que determina a paridade e a alternância de gênero nas listas de todos os partidos políticos foi sancionada, na Argentina, no ano de 2017 - válida para eleições de nível nacional. Apenas em 2018 entrou em vigor a lei $n^{\circ} 6031$, que estabelece a paridade de gênero no âmbito da cidade de Buenos Aires e ganhou validade a partir das eleições do ano de 2019. O presente trabalho, portanto, trata de um momento anterior à validade dessa lei. 
nos processos decisórios nos governos locais se encontra em déficit ${ }^{18}$. Na seção seguinte, mencionaremos uma série de obstáculos à participação feminina, que ainda parecem continuar existindo, salientando que a adoção de medidas legais em torno do tema não possibilitou o ingresso às arenas políticas de forma igualitária.

Diferentes argumentos giram em torno da demanda pelas leis de cotas. Como explicita Clara Araújo:

Pode-se identificar os [argumentos] que enfatizam aspectos simbólicos, salientando o impacto sobre o "imaginário" e a "prática política das mulheres". Os que remetem a dimensões mais teóricas, relacionados à afirmação de identidades e de interesses das mulheres como categoria e a justa representação política dos mesmos. A defesa de tais interesses exigiria mecanismos próprios de acesso às esferas legislativas ou até mesmo a inclusão de mais um critério definidor da representação, baseado na identidade de gênero. E, por fim, os de tipo mais pragmáticos, que salientam determinados resultados políticos mais imediatos, como, por exemplo, o papel positivo das cotas na legitimidade do sistema político, e/ou 0 impacto de mais candidaturas femininas sobre as tendências de voto, ampliando a 'simpatia' do eleitorado e, por consequência, produzindo ganhos partidários. (ARAÚJ0, 1998, p. 76 e 77)

A continuidade de um estudo detalhado das leis de cotas e de seus resultados se faz necessária à medida que este compreende questões indispensáveis para a discussão das assimetrias entre homens e mulheres nos espaços de poder e para a questão da ação coletiva.

\section{A participação das mulheres na política institucional}

Nas democracias liberais, as esferas públicas se constituem sob uma grande desigualdade que sempre trata de excluir os grupos mais frágeis. Se não estão totalmente excluídos, esses grupos encontram-se subordinados a um grupo dominante - representado, no caso do Brasil, por homens brancos detentores de altos rendimentos. Os segmentos subjugados, diante de um cenário de opressão, se veem obrigados a manter uma aproximação dos interesses gerais, o que acaba por afastá-los de seus próprios interesses. Essa problemática diz muito sobre os limites da participação política da mulher, assim como a falta de capital político ${ }^{19}$ desses excluídos, que agrava ainda mais o problema. (PINTO, 2001)

Fanny Tabak (1983) assinalou que as mulheres latino-americanas, bem como os setores populares, sempre tiveram acesso à participação política de forma limitada e inexpressiva. No caso específico das mulheres, a autora aponta algumas razões para os limites dessa participação no subcontinente: sistemas educacionais deficientes que incentivam o ingresso feminino em carreiras "tradicionais", como serviço social, enfermagem, ensino primário; a aceitação por parte das mulheres de que existem valores e explicações "científicas" sobre a personalidade feminina, sua capacidade intelectual, seu comportamento e sua sexualidade; e os preconceitos, tabus e estereótipos relacionados aos

18 Juntas, Rio de Janeiro, Buenos Aires e, Cidade do México somam 177 legisladores municipais, sendo 62 mulheres (o que representa um total $35 \%$ de presença feminina ao considerarmos as três cidades). Informações coletadas em agosto de 2019 com base em dados da Câmara Municipal do Rio de Janeiro, da Legislatura de la Ciudad Autónoma de Buenos Aires e do Congreso de la Ciudad de México.

19 O conceito de capital político define-se como o reconhecimento social necessário ao indivíduo para que este possa agir politicamente e para que se tenha uma autoridade específica dentro do campo político. Bourdieu reforça que "a concentração de capital político nas mãos de um pequeno grupo é tanto menos contrariada e, portanto, mais provável, quanto mais desapossados de instrumentos materiais e culturais necessários à participação ativa na política estão os simples aderentes" (BOURDIEU, 1989, p. 164). 
papéis sexuais. Embora o número da mão-de-obra feminina venha crescendo no mercado de trabalho, a maioria das mulheres ainda se dedica apenas ao trabalho doméstico nos países latino-americanos ${ }^{20}$.

Céli Pinto (2001) aponta dois quadros possíveis para a ausência de mulheres nas arenas políticas: o primeiro traz à luz a falta de compatibilidade entre os partidos políticos e as mulheres feministas. Enquanto a feminista vê sua atuação limitada pela ideologia do partido, o partido considera que a feminista não possui potencialidade de voto. $O$ segundo quadro reflete o desafio de atrair para a política mulheres que não são feministas e que estão fora de qualquer tipo de movimento social. Uma das razões para essa dificuldade está na posição ocupada pela mulher na organização do cotidiano familiar.

O trabalho privado e o isolamento na vida doméstica, que restringem a rede de contatos indispensável para o lançamento na carreira política, e a dupla (ou até tripla) jornada de trabalho são elementos centrais nessa questão. Mulheres que possuem trabalho remunerado geralmente continuam sendo as principais responsáveis pelo lar, sofrendo uma sobrecarga que reduz significativamente seu tempo para outras atividades. A estruturação da política, como ambiente masculino, e os diferentes papéis de gênero, socialmente estabelecidos, exercem influência sobre a falta de estímulo à participação feminina. (MIGUEL, 2014)

Pierre Bourdieu (2012) nos atenta para a importância de observarmos como o homem foi instituído na sociedade e como foram estruturados os cargos, sobretudo os de autoridade. A partir daí, fica evidente uma aceitação social de que é papel do homem assumir tais cargos. Como contraponto, a mulher deveria possuir não apenas o que é abertamente exigido pela descrição do posto, mas também um conjunto de características que os ocupantes masculinos atribuem usualmente ao ofício - como características físicas, formas de abordagens mais agressivas, entre outras coisas para as quais os homens foram preparados e treinados implicitamente enquanto homens.

Mesmo após a implementação das leis de cotas no Brasil, a presença da mulher em cargos eletivos no país continua sendo insatisfatória. Segundo dados do IBAM (2003), em 1992, quando a lei ainda não tinha entrado em vigor, o percentual de eleitas foi de 7,46\%. Com a Lei 9.100/1995 sancionada, estabelecendo a cota mínima de $20 \%$, o percentual subiu para $11,24 \%$ em 1996 . Nas eleições do ano 2000, já com a vigência da cota de $30 \%$ após a aprovação da Lei 9.504/1997, o percentual se manteve inalterado: $11,61 \%$. Nota-se que o preenchimento dos $30 \%$ de candidaturas femininas nas listas dos partidos não garante a eleição desse mesmo percentual de mulheres, o que ocorre devido à adoção de listas eleitorais de tipo aberto.

No entanto, postulamos que para se discutir o espaço da participação política é preciso se perguntar se as mulheres lutam somente pela presença e representação de mulheres, no sentido numérico da representação, ou se lutam pela representação de mulheres que se constituam politicamente como tal, atribuindo um sentido político à problemática.

Essa questão não é de fácil resolução: por um lado, parece adiantar pouco para as mulheres (ou para qualquer outro grupo nessa mesma situação) eleger muitas mulheres que não tenham nenhum compromisso com as causas defendidas pelo feminismo, por outro, entretanto, a pergunta que se impõe é a de que, se homens de todos os matizes ideológicos, de todas as posições sobre os mais diversos temas podem ter assento no Legislativo, por que só as "mulheres conscientes" mereceriam esse privilégio? (PINT0, 2001, p. 107)

Ainda que ocorresse um grande aumento de mulheres eleitas para as casas legislativas e que isso interferisse na questão da representação, as propostas defendidas pelo feminismo vão além. O movimento leva em consideração a atuação de um sujeito político que se constrói e se reafirma em sua condição como mulher no campo político frente às demais posições políticas e identitárias. (PINTO, 2001)

20 Indicadores do Observatório de Igualdade de Gênero da América Latina e do Caribe demonstram que mesmo mulheres que possuem renda própria ainda têm a maior parte do seu tempo ocupado pelo trabalho não remunerado. Disponível em http://oig.cepal.org/pt/indicadores/tempo-trabalho-nao-remunerado-segundo-rendimentos-proprios-sexo/ 
No Brasil, a grande capacidade feminina de se organizar nacionalmente e de influir nas políticas públicas se contrasta com os índices precários da presença de mulheres em cargos de autonomia na tomada de decisões, refletindo um grande paradoxo na dinâmica da participação política:

Ao explicar as barreiras à participação política delas, as análises têm se voltado para sua ausência e para as restrições à sua atuação; por outro lado, cabe lembrar que, a ação organizada das mulheres tem seguido cursos alternativos e produzido efeitos também no âmbito estatal. Isso explica por que, ao mesmo tempo que as mulheres e, em especial, as feministas estão sub-representadas na política, observa-se forte reação às suas pautas. Em outras palavras, estabelecem-se reações e controvérsias porque as mulheres e seus movimentos organizados têm encontrado maneiras de dar visibilidade às suas reivindicações e promover suas pautas recorrendo a campanhas, protestos, marchas e formas de participação nos espaços institucionais não restritos às disputas eleitorais. (BIROLI, 2018, n.p)

Apesar dos desafios existentes, Biroli (2018) argumenta que a atuação dos movimentos feministas em busca de reverter a questão da baixa presença feminina nos espaços formais de representação produz efeitos concretos. Em diversos momentos da história do Brasil contemporâneo, os movimentos levaram a ótica de gênero para dentro das instituições políticas, como aconteceu durante o processo de redemocratização após o regime militar (1964-1985). Com a volta da democracia e a aproximação entre movimentos e partidos políticos, os primeiros passaram a exercer maior atuação no âmbito estatal, discutindo principalmente a pauta da construção de direitos. A partir de então, o tema da sub-representação de mulheres na política institucional ganha destaque e passa a ser visto como um problema político pelos movimentos feministas e de mulheres.

\section{0 direito à cidade}

O conceito de direito à cidade surge em 1967 por meio de um ensaio do mesmo nome escrito pelo francês Henri Léfèbvre. Para o filósofo e sociólogo, a noção emerge a partir da indignação com a "crise gigantesca" fruto das mudanças radicais ocasionadas pela industrialização, e cujos impactos serão vivenciados no cotidiano da cidade. Mas, para Léfèbvre (2008), se trata também de uma crise teórica que obriga a repensar o próprio conceito de cidade, em diálogo com as forças políticas atuantes capazes de dar suporte social às mudanças necessárias. A cidade segregada em uma sociedade de classes reflete o fato de que ela é produto humano e social, pois a sociedade é constituída através de uma série de produções que a transformam em uma realidade prática e revelam o conteúdo da vida. Ou seja, a cidade tem uma origem social à medida que sua produção está diretamente ligada à reprodução das relações sociais de produção ${ }^{21}$. (CARLOS, 2020) A urbanização sustenta em grande parte a sobrevivência do capitalismo. Ela gera processos que privam as massas do acesso ao direito à cidade, expropriando os menos favorecidos e ocupando espaços para os ricos, reforçando as desigualdades e deteriorando as relações sociais. Da mesma forma, a propriedade privada propicia uma fragmentação essencial ao desenvolvimento do sistema vigente. Essa fragmentação intensifica a segregação, limita o acesso à cidade e restringe a prática socioespacial ${ }^{22}$. A urbanização transformou a qualidade de vida nas cidades em mercadoria, promovendo uma socialização humana baseada no individualismo e se distanciando da lógica de cidade como corpo político coletivo. (LÉFÈBVRE, 1999)

"[...] na produção social da própria existência, os homens entram em relações determinadas, necessárias, independentes de sua vontade; essas relações de produção correspondem a um grau determinado de desenvolvimento de suas forças produtivas materiais." (MARX, 2008, p. 47) 
Para Léfèbvre (2008), é necessário criar uma vida urbana alternativa, renovada, mais significativa e menos alienada. Essa renovação da cidade deve se dar para além da ordem capitalista, superando-a e abandonando seus procedimentos desumanizadores e segregatórios.

A ideia do direito à cidade passou por um ressurgimento que se relaciona intimamente ao que acontece nas ruas, aos movimentos sociais urbanos. Léfèbvre (2008) ressalta que esse direito só pode se concretizar através da classe operária, pois somente esta nega e refuta a estratégia de classe voltada contra ela e reúne os interesses de toda a sociedade.

Somente classes sociais capazes de tomar iniciativas revolucionárias poderão fornecer um projeto político de reforma urbana. É a pressão das massas que dará origem e reconhecimento a uma série de direitos que entrarão para os costumes da vida cotidiana, interferindo nas relações sociais. $O$ direito à cidade, entendido por Léfèbvre como "direito à vida urbana", é um desses direitos. Ele faz parte de uma ótica de revolução, de uma força política e social voltada para as necessidades sociais através da hegemonia da classe operária e de uma estratégia totalmente oposta aos interesses da classe dominante. (LÉFÈBVRE, 2008)

Só o proletariado pode investir sua atividade social e política na sociedade urbana. Só ele pode renovar o sentido da atividade produtora e criadora ao destruir a ideologia do consumo. Ele tem portanto a capacidade de produzir um novo humanismo, diferente do velho humanismo liberal que está terminando sua existência: 0 urbanismo do homem urbano para o qual e pelo qual a cidade e sua própria vida cotidiana na cidade se tornam obra, apropriação, valor de uso (e não valor de troca) servindo-se de todos os meios da ciência, da arte, da técnica, do domínio sobre a natureza material (LÉFÈBVRE, 2008, p.140).

Não podemos aqui nos estender no aprofundamento da discussão sobre as relações entre gênero e classe, mas gostaríamos de chamar a atenção para o fato de que, se as mulheres foram historicamente segregadas do "direito à vida urbana" e do direito à tomada de decisões sobre a vida urbana, as mulheres trabalhadoras, as mulheres das periferias, as mulheres negras, são duplamente segregadas, na sua condição de classe, de gênero e de raça.

David Harvey, em sua obra Cidades rebeldes: do direito à cidade à revolução urbana, faz uma releitura do conceito criado por Léfèbvre, definindo-o da seguinte forma:

0 direito à cidade é, portanto, muito mais do que um direito de acesso individual ou grupal aos recursos que a cidade incorpora: é um direito de mudar e reinventar a cidade mais de acordo com nossos mais profundos desejos. Além disso, é um direito mais coletivo do que individual, uma vez que reinventar a cidade depende inevitavelmente do exercício de um poder coletivo sobre o processo de urbanização. (HARVEY, 2014, p. 28)

Considerando que as cidades surgem da concentração geográfica e social de um excedente de produção extraído de alguém ou de algum lugar, Harvey (2014) argumenta que a urbanização pode ser entendida como um fenômeno de classe, até mesmo porque o lucro obtido fica sob o controle de poucos. Sendo assim, o autor propõe que a reivindicação pelo direito à cidade seja feita de maneira radical, exigindo algum tipo de poder configurador sobre o modo de se fazer e refazer a cidade, ou seja, sobre os processos de urbanização.

A crise da cidade e de seu modelo está diretamente ligada à crise do atual modelo econômico capitalista, pois o capitalismo precisa da urbanização para se desenvolver. O individualismo da lógica neoliberal ameaça a existência de uma política urbana coerente e fragmenta cada vez mais a cidade, dificultando o alcance dos ideais de identidade urbana, cidadania e pertencimento. (HARVEY, 2014) 
A coletividade que poderia ser promovida pela cidade para impulsionar os movimentos sociais torna-se cada vez mais distante. Para superar esse isolamento, os movimentos sociais urbanos buscam reconfigurar a imagem social da cidade se afastando dos paradigmas impostos pelo capital e pelo aparato estatal guiado pelo mundo dos negócios.

Baseando-se nas afirmações de Harvey (2014), pode-se perceber o direito à cidade no contexto atual como um direito que está majoritariamente concentrado nas mãos de uma elite política e econômica fundamentalmente masculina que constrói a cidade de acordo apenas com seus próprios interesses e necessidades. Dessa forma, pensar os vínculos (ou não) entre as organizações de muIheres e as legisladoras municipais no plano do direito à cidade torna-se essencial, principalmente quando se trata de centros urbanos tão expressivos no cenário latino-americano, como Rio de Janeiro, Buenos Aires ou Cidade do México. É nesse sentido que torna-se fundamental a participação da mulher - através de espaços representativos locais, como as câmaras de vereadores - como ativa formuladora, colaboradora e gestora de políticas públicas, participando politicamente da vida de cidades pensadas e usufruídas a partir uma lógica feminina.

\section{Considerações finais}

O espaço político ${ }^{23}$ reflete a posição e função que cada gênero tem simbolicamente dentro da sociedade, e mulheres na vida pública, seja em movimentos sociais ou como políticas que concorrem a pleitos, enfrentam um ambiente extremamente hostil e masculinizado em que uma maioria esmagadora de homens ocupa os espaços.

A discussão apresentada ao longo do trabalho nos leva à constatação de que há urgência em analisar a inserção feminina nos processos de tomada de decisão sobre a vida urbana, para além de um prisma em que a mulher é vista como mero objeto das políticas públicas, enquanto ao homem atribui-se a função de planejador.

Concluímos que pensar a mulher presente e atuante na política municipal, numa perspectiva feminista, nos permite pensá-la como planejadora do espaço urbano e da vida das cidades, avaliando de maneira mais clara suas pretensões, interesses e demandas. Por esse caminho, torna-se possível compreender a presença feminina em uma cidade em que elas também teriam autonomia no que diz respeito aos seus direitos como cidadãs e às escolhas sobre o acesso e a função do espaço público, não se limitando apenas à posição de "usuárias" de uma cidade idealizada, ocupada e erguida pelo mundo masculino.

\footnotetext{
23 O conceito de espaço político, neste trabalho, é entendido conforme a análise de Andrea Cornwall (2002), em que o espaço político possui uma conotação material e ganha vida através do ato da participação. Traduz-se, por exemplo, nas "arenas" políticas e de governança, que são espaços onde há disputas entre vozes e entre ideias que representam diferentes interesses e atores. O autor diz que "o "espaço político" não é apenas algo que pode ser ocupado, assumido ou preenchido, mas algo que pode ser criado, aberto e remodelado." (COMWALL, 2002, p. 2)
} 


\section{Referências}

ARAÚJO, Clara. Mulheres e Representação Política: a experiência das cotas no Brasil. Revista Estudos Feministas, vol. 6, nº 4, pp. 71-91, 1998.

BIROLI, Flávia. Gênero e desigualdades: limites da democracia no Brasil. $1^{\text {a }}$ edição. São Paulo: Boitempo, 2018.

BOURDIEU, Pierre. A dominação masculina. 11a edição. Rio de Janeiro: Bertrand Brasil, 2012.

A representação política. Elementos para uma teoria do campo político. In: BOURDIEU, Pierre. O Poder Simbólico. Lisboa: Difel, 1989, pp.163-207.

CÂMARA MUNICIPAL DO RIO DE JANEIRO. Disponível em: <http://www.camara.rj.gov.br>. Acesso em: 05 maio 2019.

CARLOS, Ana Fani Alessandri. Henri Léfèbvre: o espaço, a cidade e o "direito à cidade". Revista Direito e Práxis, vol. 11, nº 1, pp. 349-369, Rio de Janeiro, 2011.

CEPAL (Comisión Económica para América Latina y el Caribe). Horizontes 2030: la igualdad en el centro del desarrollo sostenible. (LC/G.2660/ Rev.1), Santiago, 2016.

CISNE, Mirla. Feminismo e consciência de classe no Brasil. São Paulo: Cortez, 2015.

CONGRESO DE LA CIUDAD DE MÉXICO. Disponível em: <https://www.congresocdmx.gob.mx>. Acesso em: 05 maio 2019.

CORNWALL, Andrea. Making spaces, changing places: situating participation in development. IDS Working Paper 170. Institute of development studies at the University of Sussex. Brighton, 2002.

FALQUET, Jules. Por las buenas o por las malas: las mujeres en la globalización. Bogotá: Universidad Nacional de Colombia. Facultad de Ciencias Humanas, 2011.

HALL, P. The World Cities. New York: McGraw-Hill, 1966.

HARVEY, David. Cidades rebeldes: do direito à cidade à revolução urbana. São Paulo: Martins Fontes, 2014.

IBAM (Instituto Brasileiro de Administração Municipal). Participação feminina na construção da democracia: um levantamento do resultado das eleições municipais (1992 a 2000) e estaduais e federais (1994 a 2002). Rio de Janeiro: Ibam, 2003.

LÉFÈBVRE, Henri. A Revolução Urbana. Belo Horizonte: UFMG, 1999.

O Direito à Cidade. $5^{\text {a }}$ edição. São Paulo: Centauro, 2008.

LEGISLATURA CIUDAD AUTÓNOMA DE BUENOS AIRES. Disponível em: $\leq$ https://www.legislatura.gov.ar>. Acesso em: 05 maio 2019.

MADURO, Lídice Aparecida Pontes. Os representantes do município do Rio de Janeiro. Revista de Ciência Política, v. 23, no 1, Rio de Janeiro, 1980.

MARQUES, Danusa. $\mathbf{O}$ que são as cotas para mulheres na política e qual é sua importância? Gênero e Número, 2018. Disponível em: <http://www.generonumero.media/o-que-sao-as-cotas-para-mulheres-na-politica-e-qual-e-sua-importancia/>. Acesso em: 07 maio 2020.

MARQUES, Teresa Cristina de Novaes. O voto feminino no Brasil. Brasília: Câmara dos Deputados, Edições Câmara, 2018.

MARSHALL, T. H. Cidadania, classe social e status. Rio de Janeiro: Zahar Editores, 1967.

MARX, Karl. Contribuição à crítica da economia política. 2a edição. São Paulo: Expressão Popular, 2008. 
MIGUEL, Luís Felipe. Gênero e representação política. In: MIGUEL, Luís Felipe; BIROLI, Flávia. Feminismo e Política. $1^{\text {a }}$ edição. São Paulo: Boitempo, 2014, n.p.

OBSERVATÓRIO DE IGUALDADE DE GÊNERO DA AMÉRICA LATINA E DO CARIBE. Leis de cotas e paridade. Disponível em: <https://oig.cepal.org/pt/leis/leis-de-cotas $>$. Acesso em: 05 maio 2019.

Mulheres vereadoras eleitas. Disponível em: $<$ https://oig.cepal.org/pt/indicadores/mulheres-vereadoras-eleitas $>$. Acesso em: 05 maio 2019.

Tempo de trabalho não remunerado segundo rendimentos próprios por sexo. Disponível em: <https://oig.cepal.org/pt/indicadores/tempo-trabalho-nao-remunerado-segundo-rendimentos-proprios-sexo $>$. Acesso em: 22 agosto 2019.

ONU MULHERES. Convenção sobre a eliminação de todas as formas de discriminação contra a mulher. Disponível em: $\leq$ http://www.onumulheres.org.br/wp-content/uploads/2013/03/ convencao cedaw1.pdf $>$. Acesso em: 26 julho 2019.

PINTO, Céli. Paradoxos da participação política da mulher no Brasil. Revista USP, n 49, pp. 98-112, São Paulo, 2001.

SILVA, Carmen. Pensar o futuro, bem viver o presente. Cadernos de Crítica Feminista, ano V, no 4, dez. 2011.

SOUZA-LOBO, Elisabeth. A classe operária tem dois sexos: trabalho, dominação e resistência. São Paulo: Fundação Perseu Abramo/Secretaria Municipal de Cultura/Brasiliense, 2011.

TABAK, Fanny. Autoritarismo e participação política da mulher. Rio de Janeiro: Edições Graal, 1983. 
